\title{
Measurement of the Body Temperature During Intensive Short-Term Dynamic Psychotherapy: A Case Study
}

\section{Davood Manavipour*, Yasamin Roshani}

${ }^{1}$ Department of Psychology, Garmsar Branch, Islamic Azad University, Garmsar, Iran

\section{A BSTRACT}

Introduction: The purpose of this study was to measure the body temperature changes in the process of central dynamic sequence in intensive short-term dynamic psychotherapy. Case Description: The sample consisted of a patient who was voluntarily chosen. The research design was case study method. Results: The body temperature (hand temperature, forehead temperature) was measured during treatment protocol, using biofeedback machine. A nonparametric test $\mathrm{K}$ independent sample was used for data analysis. Conclusion: The intensive short-term dynamic psychotherapy changes the body temperature. The body temperature is a sign to review the protocol and determine the level of anxiety and the patient's defenses.

\section{Key words:}

1. Body Temperature Changes

2. Biofeedback, Psychology 3. Anxiety

* Corresponding Author: Davood Manavipour

E-mail: Manavipor53@yahoo.com 


\title{
سنجش دماى بدن در طول رواندرمانى يويشى فشرده كوتاهمدت: يك مطالعهُ موردى
}

\author{
داود معنوى يور"، ياسمين روشنى \\ 'مروه روانشناسى، واحد كَرمسار، دانشكاه آزاد اسلامى، كرمسار، ايران
}

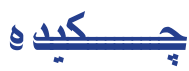

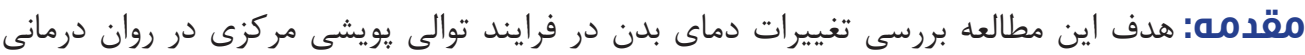

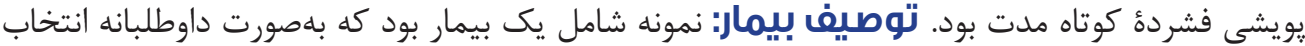

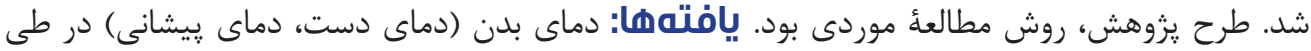

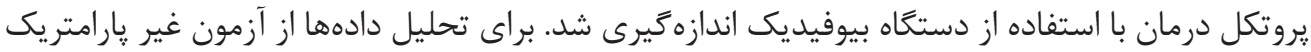

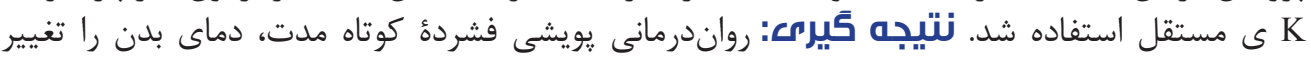

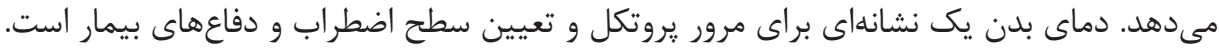

كليد وازهها:

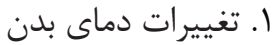

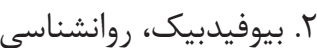

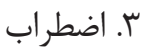


نشانههاى جسمى و روانشناختى خاصى دارد. نشانههاى

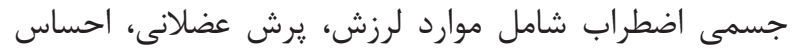

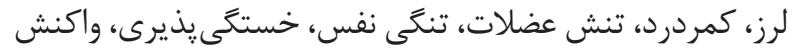

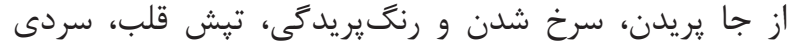

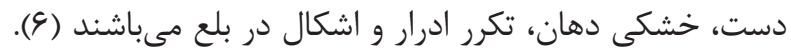
نشانهای روانشناختى اضطراب نيز موارد احساس، وحشى وحشت،

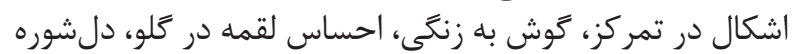

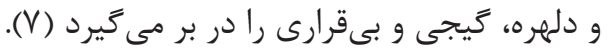

در مبانى نظرى ISTDP سه كانال براى تخلية اضطراب وجود

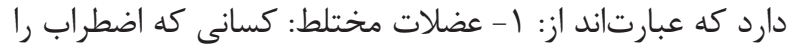

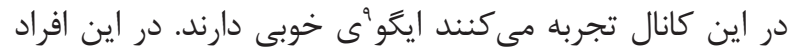

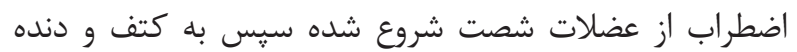

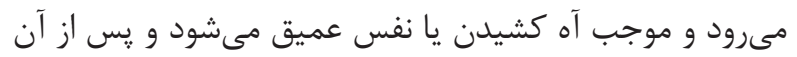

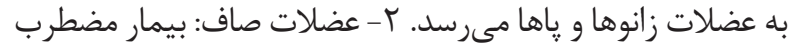

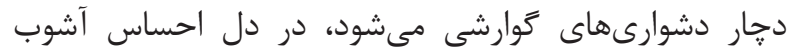

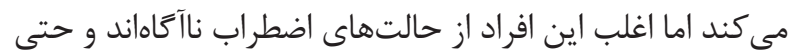

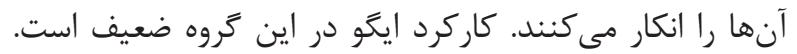

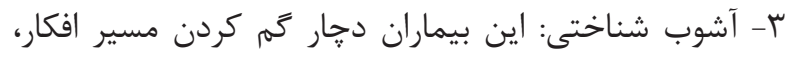

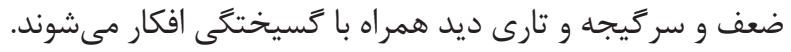

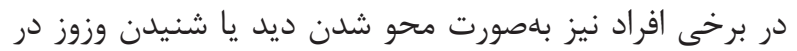

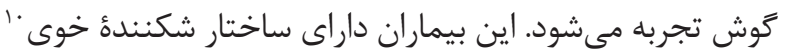

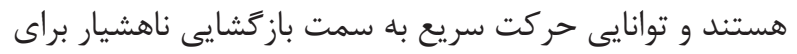

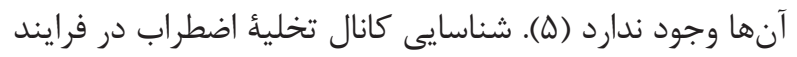
ISTDP

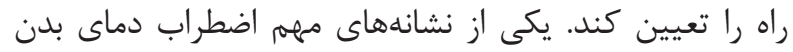

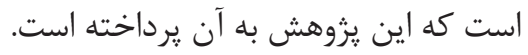

دماى بافتهاى عمقى و دماى مر كزى بدن بهطور كموبيش دقيق

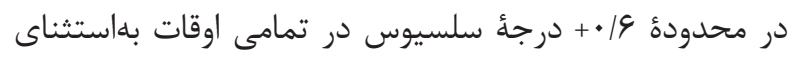

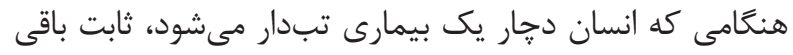

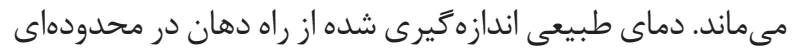

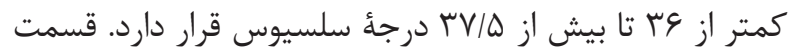

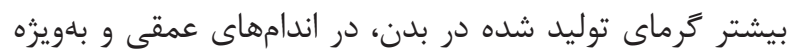

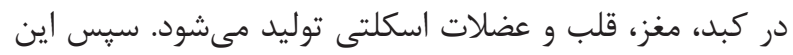

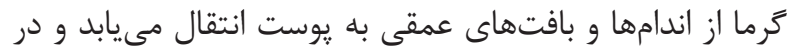

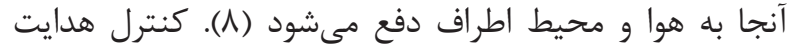

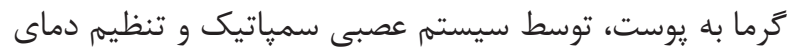

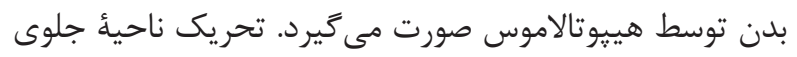

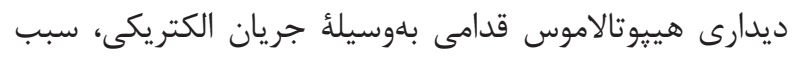

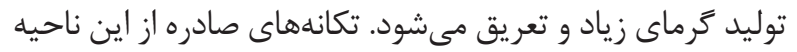

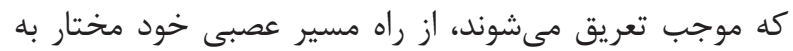

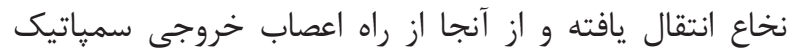

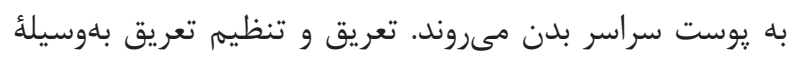

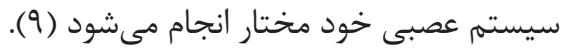

${ }^{1}$ Intensive short term dynamic psychotherapy (ISTDP)

${ }^{2}$ Drive reduction

${ }^{3}$ Superego

${ }^{4}$ Pressure

${ }^{5}$ Challenge

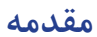

روان درمانى يويشى فشرده كوتاه مدت (ISTDP)'، بيانكَر تغيير

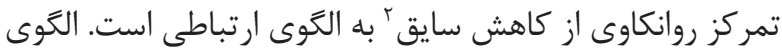

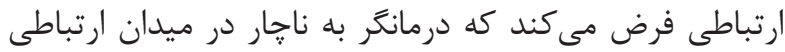

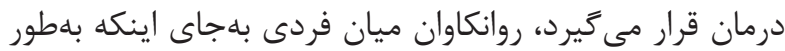

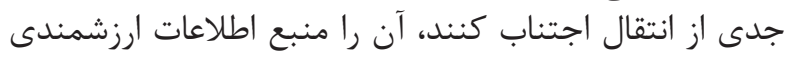

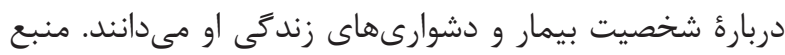

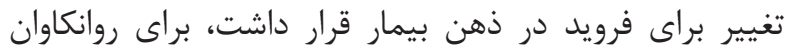

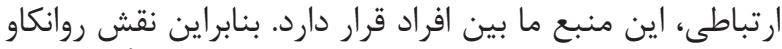

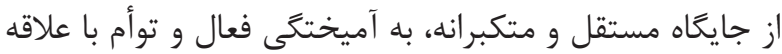

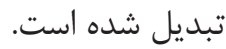

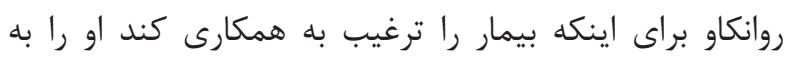

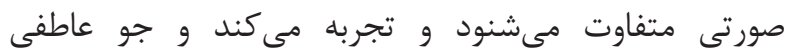

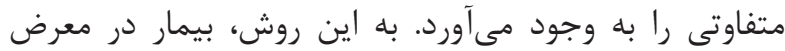

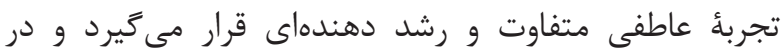

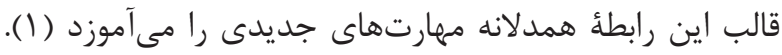

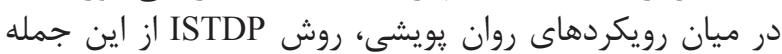

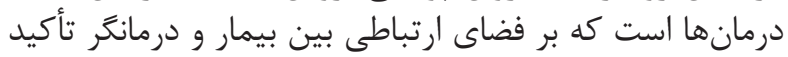

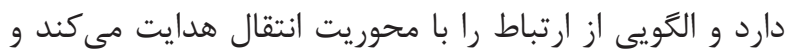

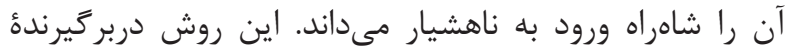

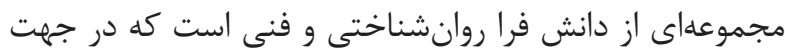

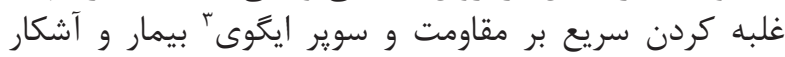

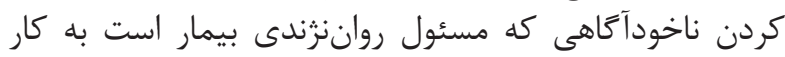

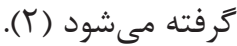

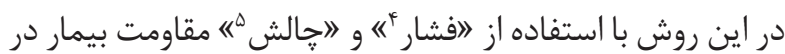

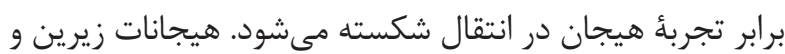

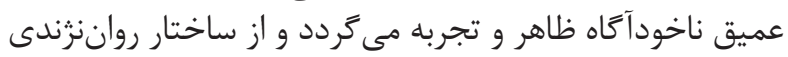

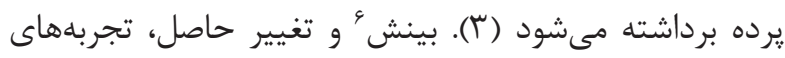

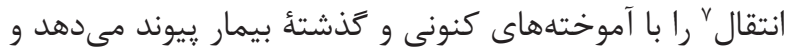

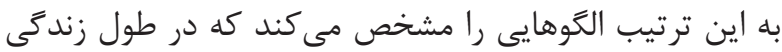

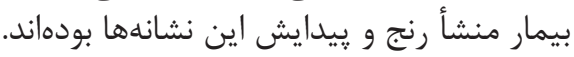

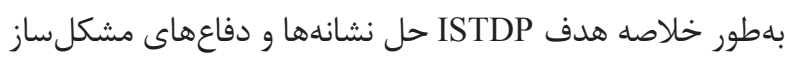

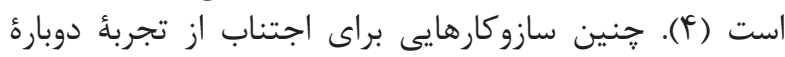

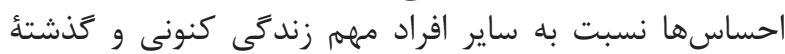

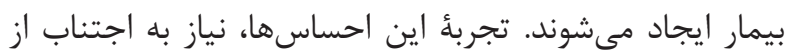

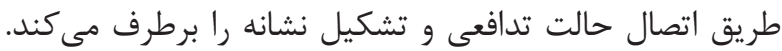

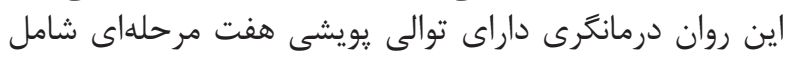

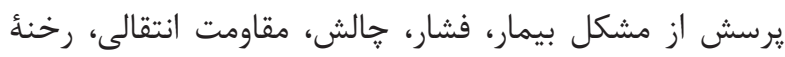

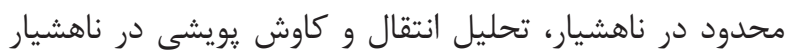

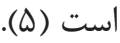

تنيدگى ميان احساس، اضطراب و دفاع، تعارض هاى درون درون روانى

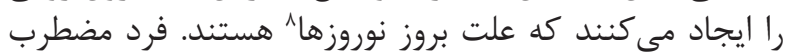

\footnotetext{
${ }^{6}$ Insight

${ }^{7}$ Transferences

${ }^{8}$ Neurosis

${ }^{9}$ Ego

${ }^{10}$ Fragile characteristic
} 


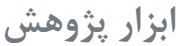

GSR- TEMP- HR) دستخاه بيوفيدبك جهماركاناله (biofeedback

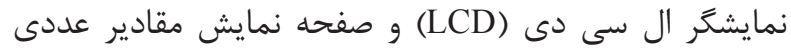

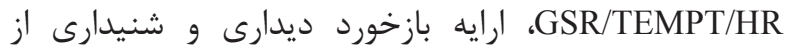

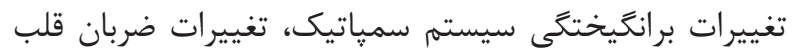

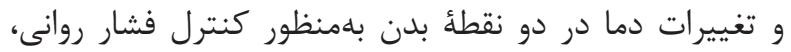

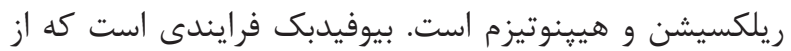

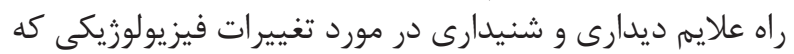

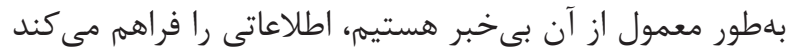
و به آكاهى ما معىرساند.

\section{شرح جلسات روان :ويشى كوتاه مدت فشرده:}

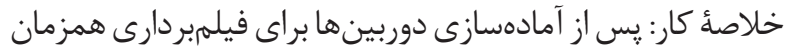

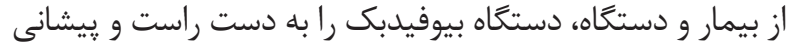

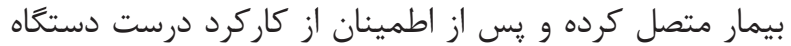

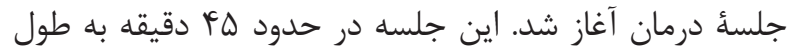

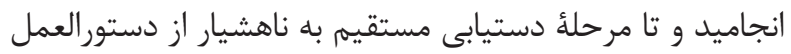

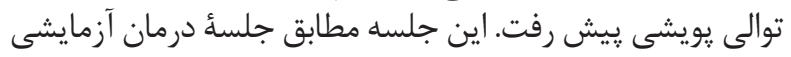

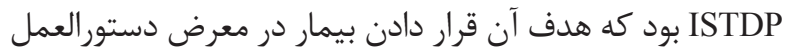
درمان و ارزيابى تناسب بيمار براى اين رادي روش درمار درمان است.

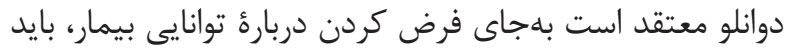

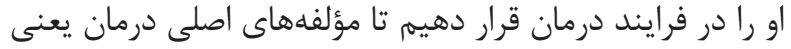

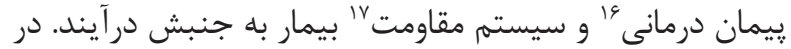

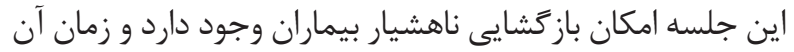

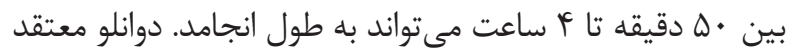

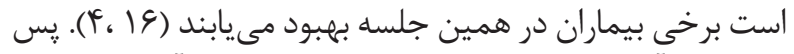

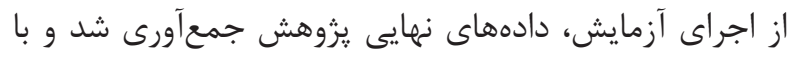

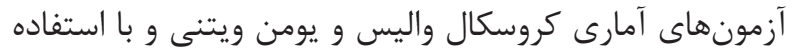

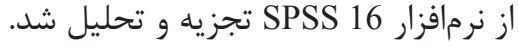

يافته ها

همان طورى كه در جدول ا ملاحظه مىشود ميانگين و انحراف

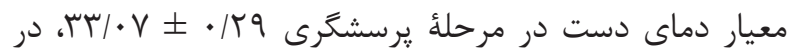

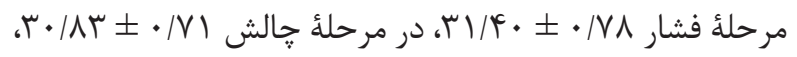

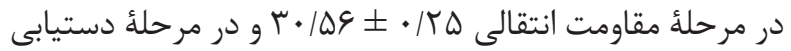

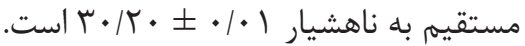

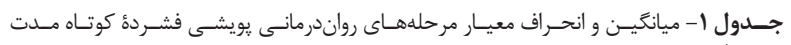

\begin{tabular}{|c|c|c|c|}
\hline تعداد & انحر اف معيار & ميانكين & متغير شاخصهاى آمارى \\
\hline If & $\cdot 1 / 99$ & 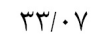 & مر حلهُ يرسشَّى \\
\hline ro & $\cdot / \mathrm{V} \wedge$ & $r M / 4$. & مر حلة فشار \\
\hline ra & $\cdot|V|$ & $r \cdot / \Lambda r$ & مرحلة جالش \\
\hline rd & $\cdot / 1 / \Delta$ & $r \cdot \mid \Delta \varphi$ & مر حله مقاومت انتقالى \\
\hline ثمث ن & $\cdot 1 \cdot 1$ & $r \cdot / r$. & دستيابى مستقيم به ناهشيار \\
\hline
\end{tabular}

${ }^{11}$ Caso

12 Trial therapy

${ }^{13}$ Kruskal-Wallis

${ }^{14}$ U Mann-Whitney

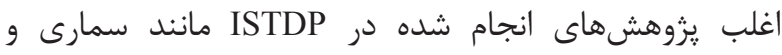

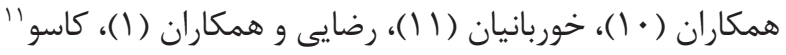

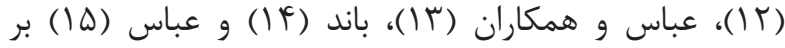

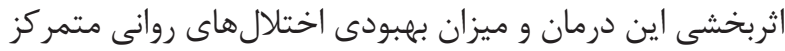

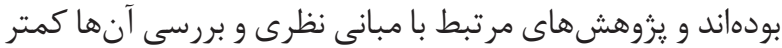

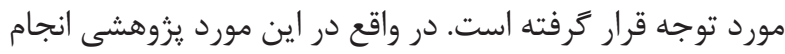

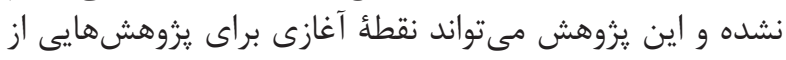

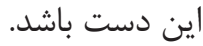

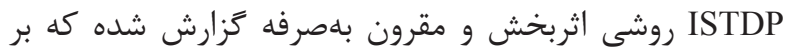

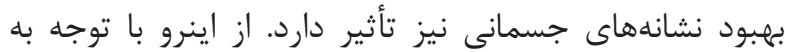

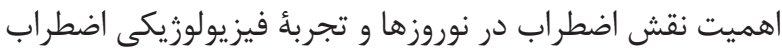

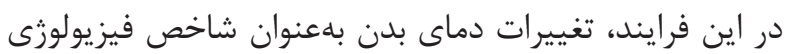

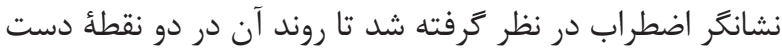

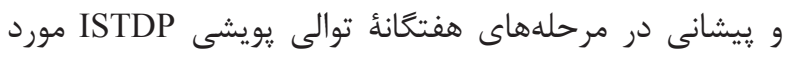

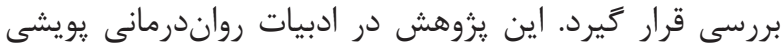
بديع است و يزوهشى مشابه آن يافت نشدر إند

توصيف بيمار

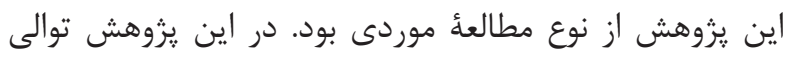

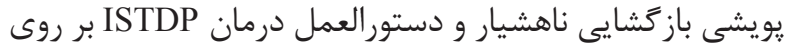

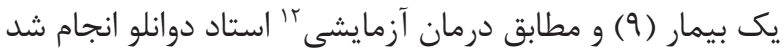

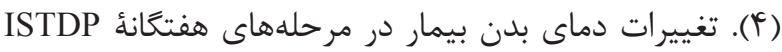

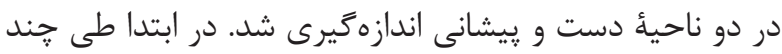

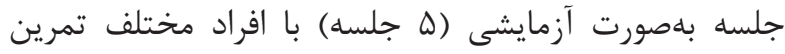

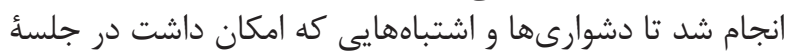

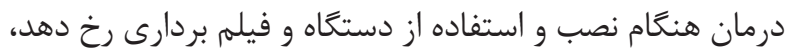

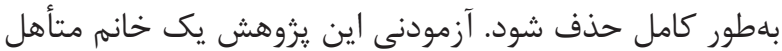

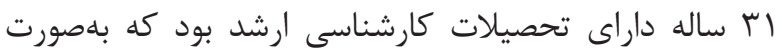

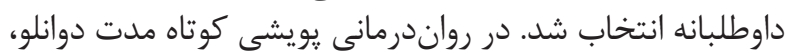

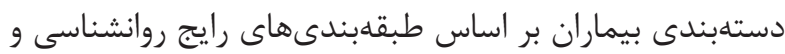

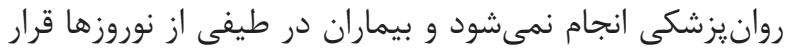

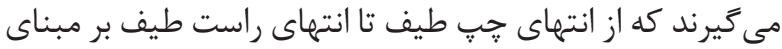

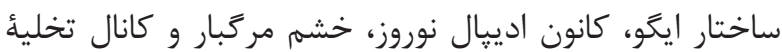

اضطراب به ينج طبقه تقسيم مىشوند (f).

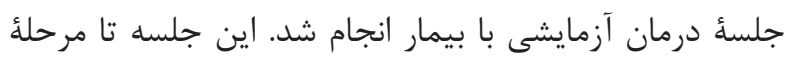

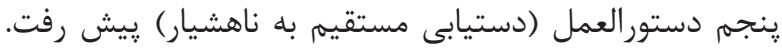

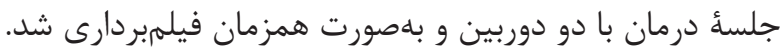

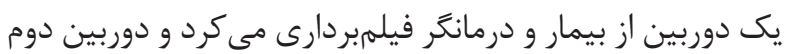

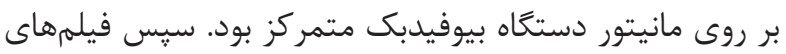

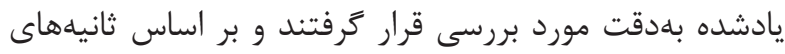

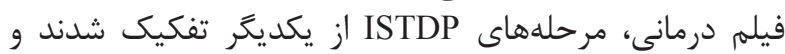

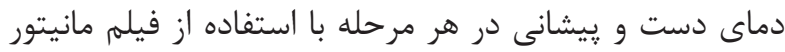

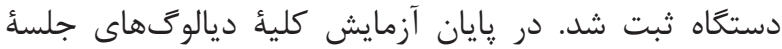

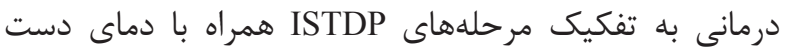

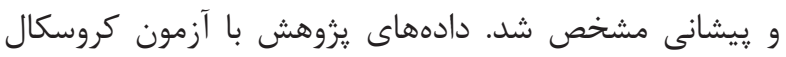

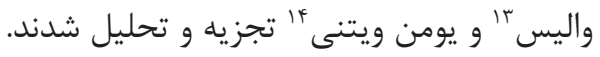

\footnotetext{
${ }^{15}$ GSR-TEMP- HR biofeedback

${ }^{16}$ Therapeutic Alliance

${ }^{17}$ Resistance
} 
در مرحلة يرسشكرى است.

براى بررسى تفاوت بين مرحلهها، با استفاده از آزمون يومن مرند

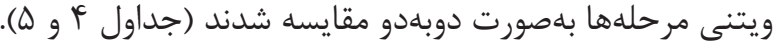

جدول F- مقايسٔ دوبددوى مرحلههاي يروتكل به تفكيك دماى دست.

\begin{tabular}{|c|c|}
\hline سطح معنىدارى & مرحلههاى بروتكل \\
\hline$\cdot 1 \cdot 1$ & يرسشَرى و فشار \\
\hline $.1 \cdot 1$ & ״رسشكرى و خالش \\
\hline $.1 \cdot 1$ & ״رسشَّى و مقاومت انتقالى \\
\hline$\cdot 1 \cdot 1$ & يرسشكرى و بازَشايى ناهشيار \\
\hline$\cdot 1 \cdot 1$ & فشار و جالش \\
\hline $.1 \cdot 1$ & فشار و مقاومت انتقالى \\
\hline$\cdot 1 \cdot r$ & فشار و بازگشايى ناهشيار \\
\hline .109 & جالش و مقاومت انتقالى \\
\hline.$/ 1 \mathrm{~V}$ & جالش و بازگشايى ناهشيار \\
\hline$-3 \cdot 1 \cdot 4$ & مقاومت انتقالى و بازگشايى ناهشيار \\
\hline
\end{tabular}

جدول هـ -مقايسٔ دوبهدوى مر حلههاى يروتكل به تفكيك دماى بيشانى.

\begin{tabular}{|c|c|}
\hline سطح معنى دارى & مرحلههاى بروتكل \\
\hline$\cdot 1 \cdot 1$ & يرسشگرى و فشار \\
\hline$\cdot 1 \cdot 1$ & يرسشگرى و خالش \\
\hline$\cdot 1 \cdot$ & يرسشگرى و مقاومت انتقالى \\
\hline$\cdot 1 \cdot 1$ & يرسشَّى و بازگشايى ناهشيار \\
\hline$\cdot 1 \cdot 1$ & فشار و حالش \\
\hline$\cdot 1 \cdot 1$ & فشار و مقاومت انتقالى \\
\hline$\cdot 1 \cdot r$ & فشار و بازگشايى ناهشيار \\
\hline$\cdot / \vee \wedge$ & جالش و مقاومت انتقالى \\
\hline 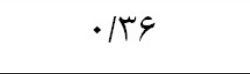 & جالش و بازگشايى ناهشيار \\
\hline$\cdot 1 \cdot V$ & مقاومت انتقالى و بازگشايى ناهشيار \\
\hline
\end{tabular}

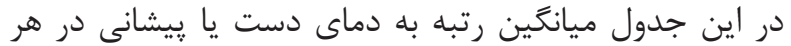

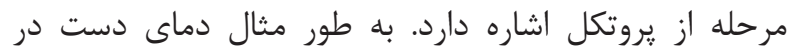

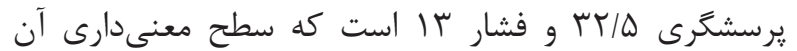

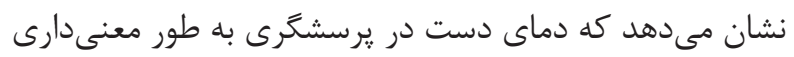

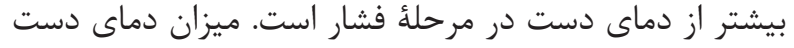

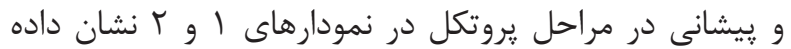

شده است.

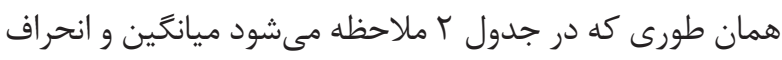

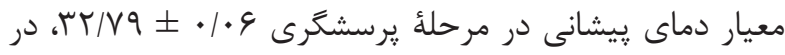

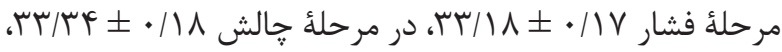
در مرحلة مقاومت انتقالى

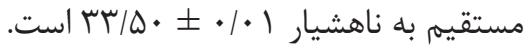

جدول r - ميانكَين و انحراف معيار مرحلههاى روان درمانى يويشى فشردة كوتاه مدت در دماى

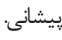

\begin{tabular}{|c|c|c|c|}
\hline تعداد & انحراف معيار & ميانكين & متغير \\
\hline If & $.1 \cdot 9$ & $r r / v q$ & مرحلهُ يرسشعرى \\
\hline ro &.$/ 1 \mathrm{~V}$ & 1/ון & مرحلة فشار \\
\hline ra & $\cdot / 1 \wedge$ & 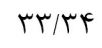 & مرحلهُ جالش \\
\hline$r \Delta$ & .111 & TH/TY & مرحلئ مقاومت انتقالى \\
\hline r & $\cdot 1 \cdot 1$ & . & دستيابى مستقيم به ناهشيار \\
\hline
\end{tabular}

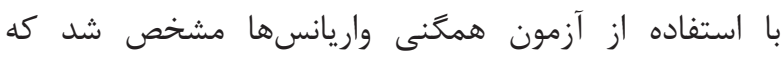

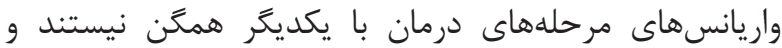

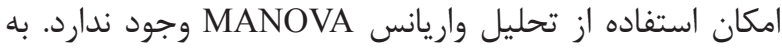

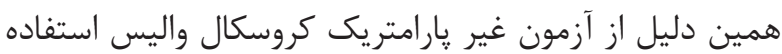

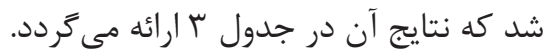

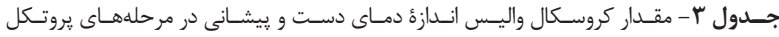
روان درمانسى يويشى فشـردة كوتـاه مـدت

\begin{tabular}{|c|c|c|c|}
\hline$P$ & df & Chi-Square & متغير \\
\hline $.1 \cdot \cdot 1$ & p & 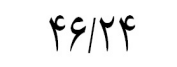 & دماى دست \\
\hline $1 \cdot \cdot 1$ & $k$ & FV/V & دماى پيشانى \\
\hline
\end{tabular}

همانطور كه در جدول r ملاحظه مى مردد،

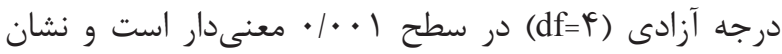

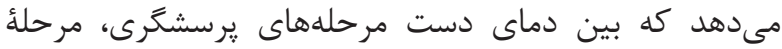

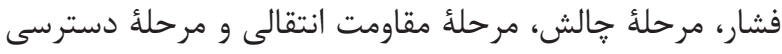

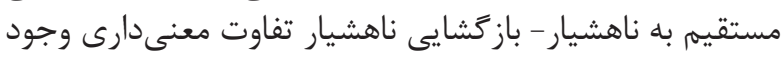

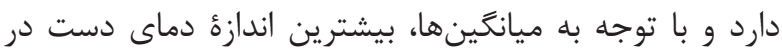

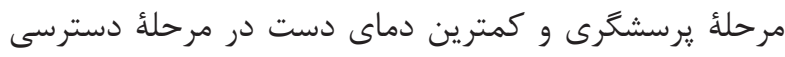
مستقيم به ناهشيار -باز كشايى ناهشيار است.

همجنين در جدول ب ملاحظه مى مردد،

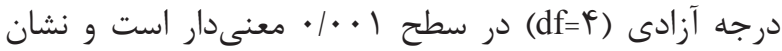

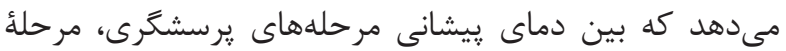

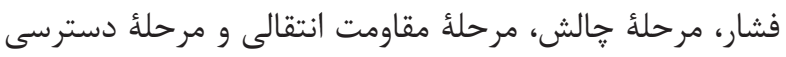

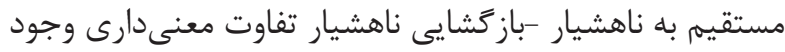

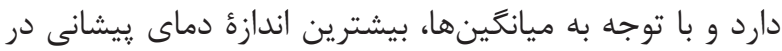

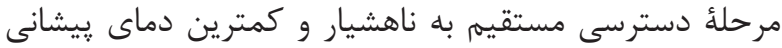




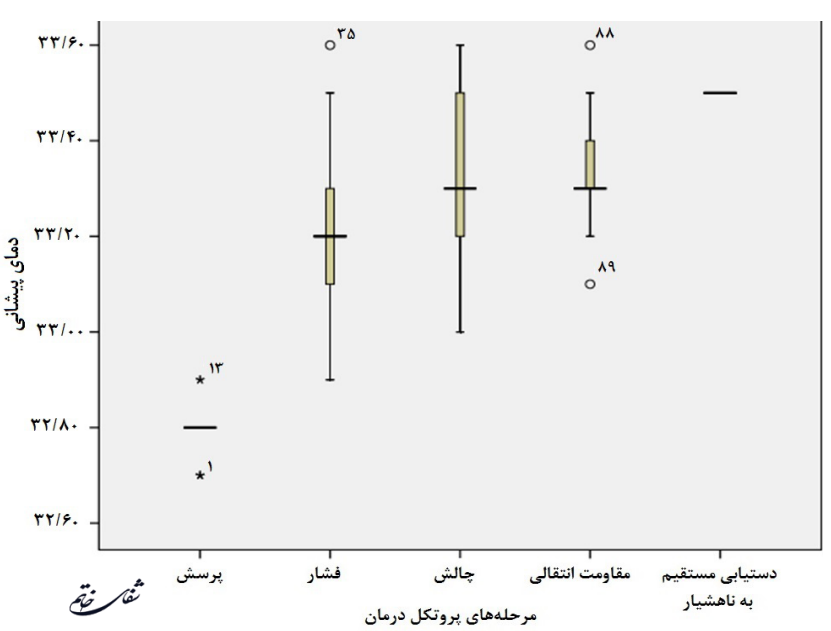

نمودار r - ميزان دماى بيشانى در مرحلههاى ه كَانه.

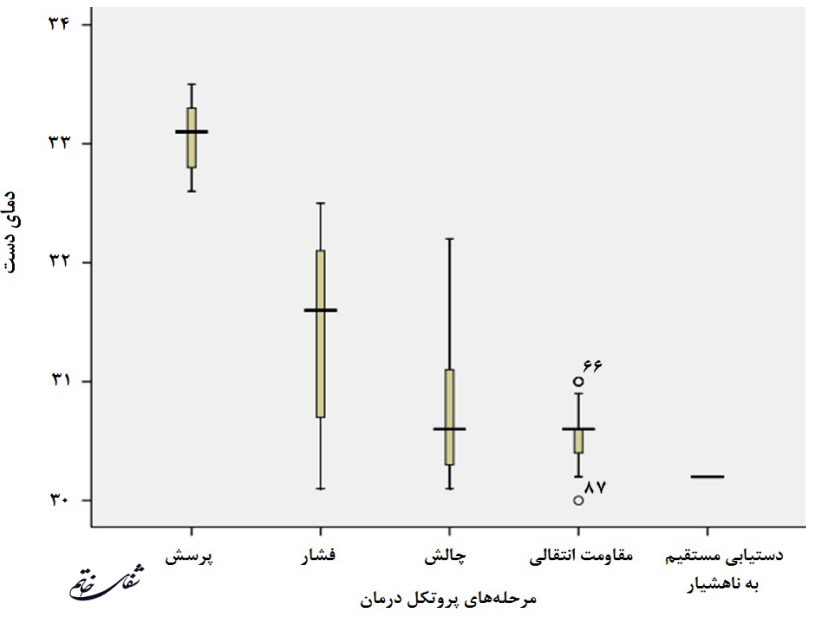

نمودار ا- ميزان دماى دست در مرحلههاى ه كانه.

شدن علايم و مهارنايذير بودن مشكل و كاركرد مختل فرد،

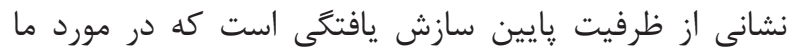

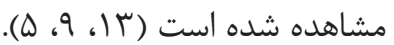

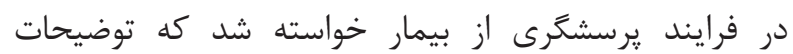

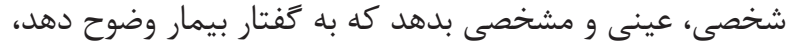

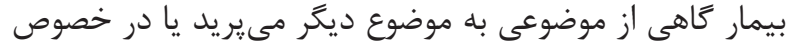

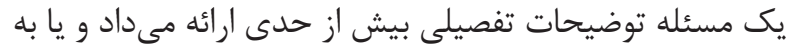

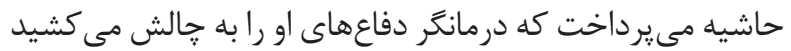

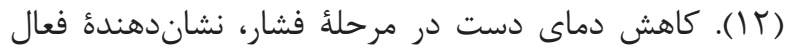

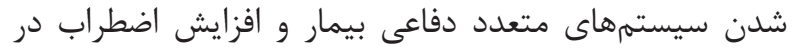

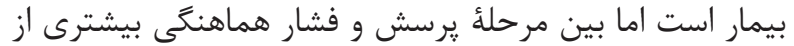

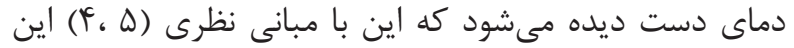
روش هماهنخ است.

در مرحلههاى خالش و مقاومت انتقالى ميانگَين دماى دست

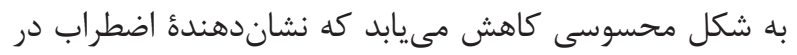

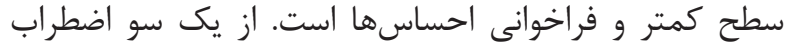

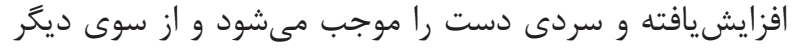

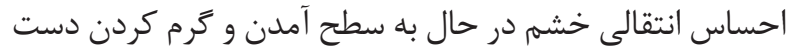

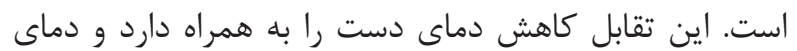

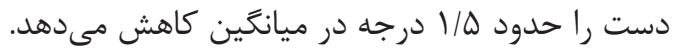

در مرحلة ينجم توالى يويشى، دستيابى مستقيم به ناهشيار كه

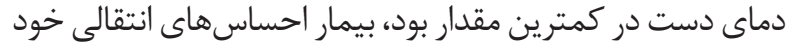

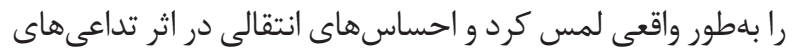

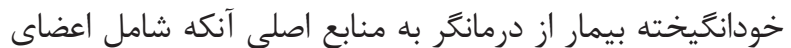

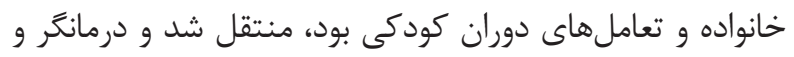

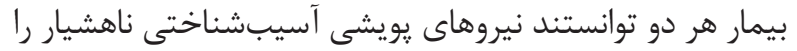

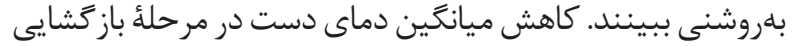

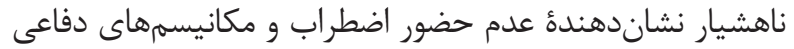

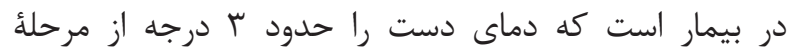

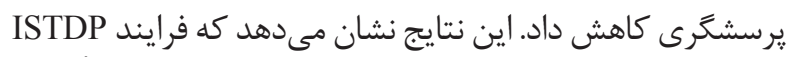
با تغييرات منظمه در دماى دست همرئ دمراه است است و اين ائ يافته تأييدى

\section{بحث و نتيجه}

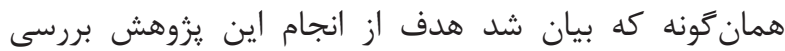

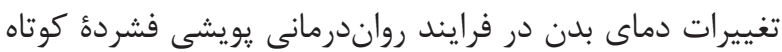

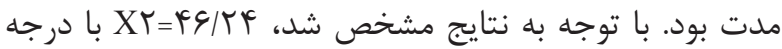

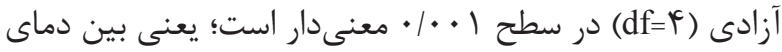

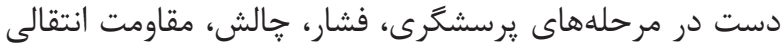

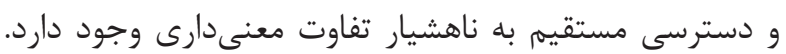

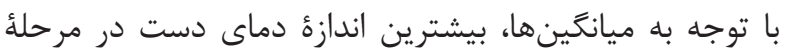

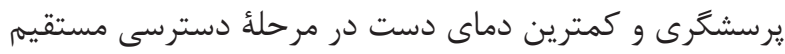

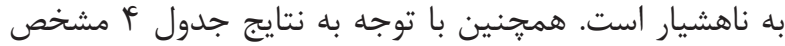

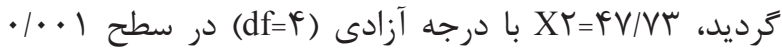

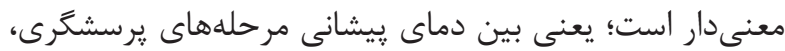

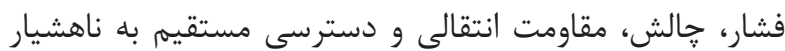

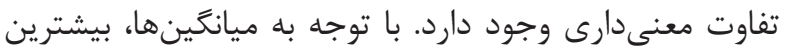

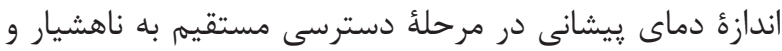

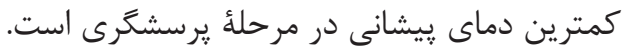

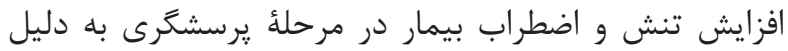

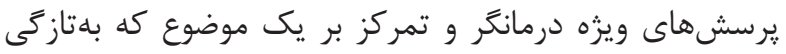

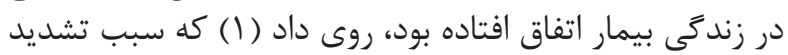

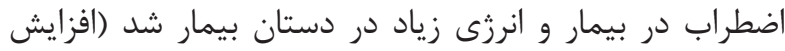

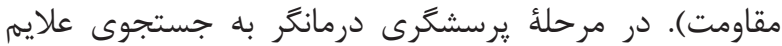

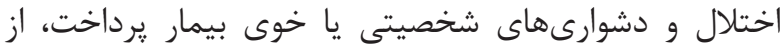

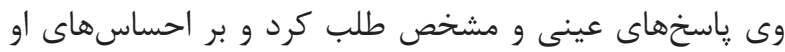

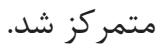

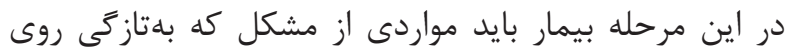

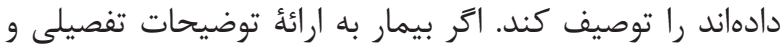

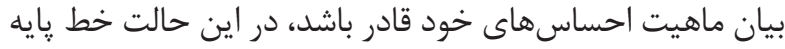

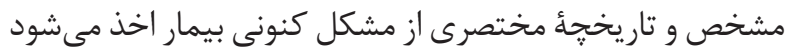

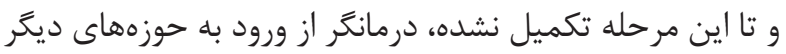

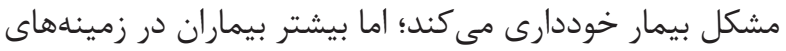

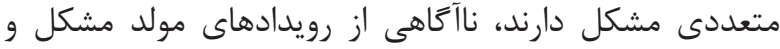

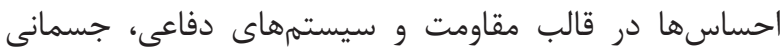


به مقدار ميانگينها دماى بدن در مرحله فشار بيشتر از جالش

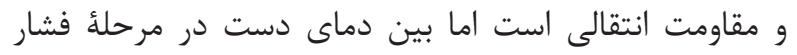

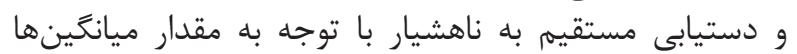

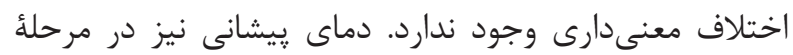

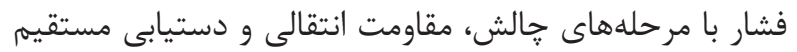

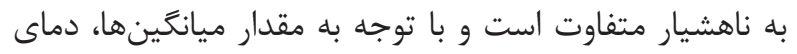

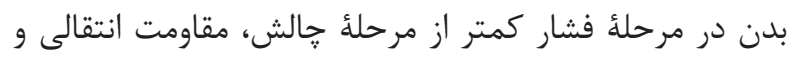

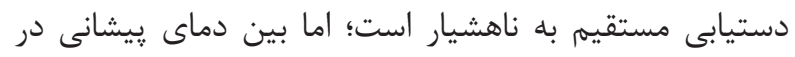

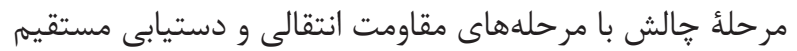

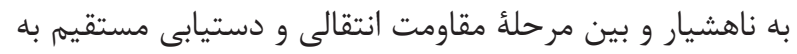

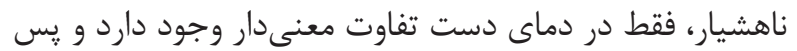

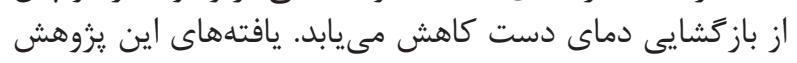

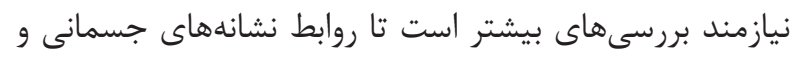

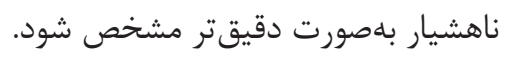

$$
\text { تشكر و قدردانى }
$$

سياس از يروفسور حبيب دوانلو كه با مفهومسازى روش

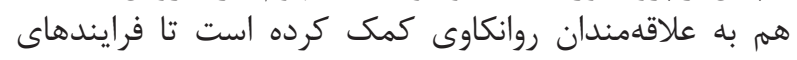

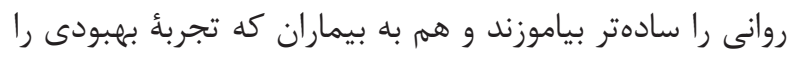

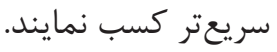

Rezaee M, Mohamadkhani P, Dolatshahi B. Relation of transference interpretation to outcome of depression in short term psychodynamic psychotherapy. J Rehabil. 2010; 11 (2): 67-77.

Prochasca J, Norcras J. Psychotherapy theories. Tehran: Roshd Press. 2011.

Abbass AA, Hancock JT, Henderson J, Kisely S. Shortterm psychodynamic psychotherapies for common mental disorders. Cochrane Database Syst Rev. 2006; (4): CD004687.

Davanloo H. Unlocking the Unconscious: Selected Papers of Habib Davanloo. $2^{\text {nd }}$ ed, Arjmand Press. 2010.

Ghgorbani N. Intensive short-term dynamic psychotherapy: basics abs technical. SAMT. 2008.

6. Wily S. The efficacy intensive short term dynamic psychotherapy on the resilience cardiovascular. Physiol Behav. 2012; 68 (5): 715- 22.

7. Geras A. Short-interval test retest interrater reliability of the Structured Clinical Interview for DSM-III-R personality disorders (SCID-II) in outpatients. J Pers Disord. 1999; 12: 138- 48.

8. Bahson A. Effect Stress management training for

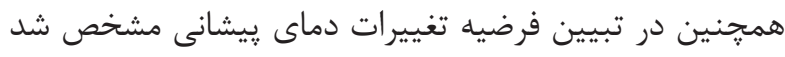

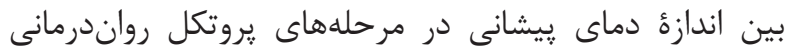

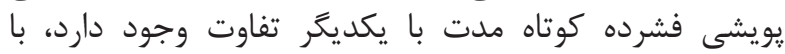

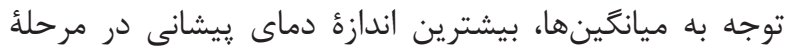

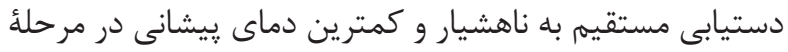

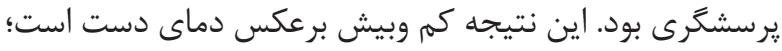

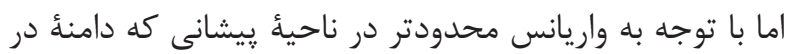
حدود ا نمرهاى از يراكند

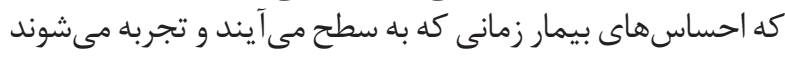

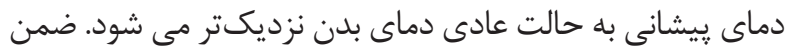

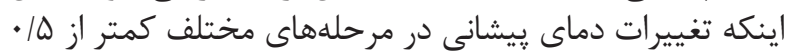

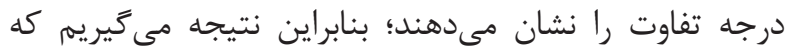

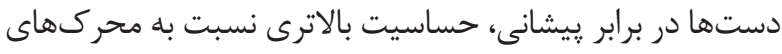

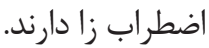

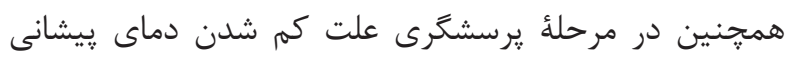

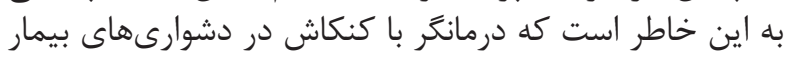

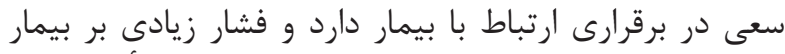

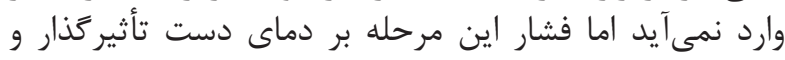

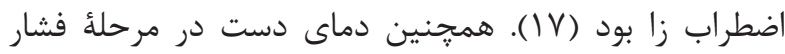

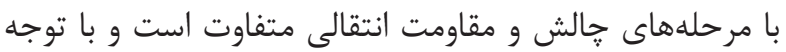

منابع

youth in divorcee. YSA. 2011; 28(1): 28-38.

9. Manavipour D, Ansari M. Measurement of heartbeat changes in process of intensive short-term dynamic psychotherapy. JCEN, 2014; 1(1): 60-8.

10. Semarey M, Ghaedi R, Mohammad Khani B. The effectiveness of short-term psychodynamic therapy to reduce anxiety in patients with generalized anxiety. $\mathrm{J}$ Clin Psychol. 1391; 4(4): 45-28.

11. Khvrbanyan M. Intensive short-term dynamic psychotherapy effectiveness in reducing symptoms in patients with depression and the mechanisms of defense. MA thesis. Islamic Azad University Garmsar Branch . 2012.

12. Caso W. Whither counter transeference in couples and family therapy: A Systemic perspective. J Clin Psychol. 2013; (57): 1029-40.

13. Abbass AA, Hancock JT, Henderson J, Kisely S. Short-term psychodynamic psychotherapies for common mental disorders. Cochrane Database Syst Rev. 2006; (4): CD004687.

14. Bond M. Psychodynamic psychotherapy in the treatment of mood disorders. Curr Opin Psychiatry. 2006; 19(1): 40-3. 
15. Abass A. Intensive short-term dynamic psychotherapy in a private psychiatric office: Clinical and cost effectiveness. Am J Psychother. 2002; 56: 225-32.

16. Manavipour, D. Defense mechanisms in Candidate patients for intensive short term dynamic psychotherapy. Journal of Behavioral sciences in Asia. 2013; 1(2): 1-5.

17. Davanloo H. Intensive short-term dynamic psychotherapy. 2nd ed, Arjmand Press. 2012. 